\title{
Environmental Enrichment Rescues Binocular Matching of Orientation Preference in the Mouse Visual Cortex
}

\author{
Jared N. Levine, ${ }^{1,2}$ Hui Chen, ${ }^{1}$ ํu Gu, ${ }^{1}$ and ${ }^{-}$Jianhua Cang ${ }^{1}$ \\ ${ }^{1}$ Department of Neurobiology, ${ }^{2}$ Interdepartmental Neuroscience Program, Northwestern University, Evanston, Illinois 60208
}

\begin{abstract}
Neural circuits are shaped by experience during critical periods of development. Sensory deprivation during these periods permanently compromises an organism's ability to perceive the outside world. In the mouse visual system, normal visual experience during a critical period in early life drives the matching of individual cortical neurons' orientation preferences through the two eyes, likely a key step in the development of binocular vision. Here, in mice of both sexes, we show that the binocular matching process is completely blocked by monocular deprivation spanning the entire critical period. We then show that 3 weeks of environmental enrichment (EE), a paradigm of enhanced sensory, motor, and cognitive stimulation, is sufficient to rescue binocular matching to the level seen in unmanipulated mice. In contrast, 6 weeks of conventional housing only resulted in a partial rescue. Finally, we use two-photon calcium imaging to track the matching process chronically in individual cells during EE-induced rescue. We find that for cells that are clearly dominated by one of the two eyes, the input representing the weaker eye changes its orientation preference to align with that of the dominant eye. These results thus reveal ocular dominance as a key driver of the binocular matching process, and suggest a model whereby the dominant input instructs the development of the weaker input. Such a mechanism may operate in the development of other systems that need to integrate inputs from multiple sources to generate normal neuronal functions.
\end{abstract}

Key words: adult plasticity; critical period; environmental enrichment; orientation selectivity; two-photon imaging

Significance Statement

Critical periods are developmental windows of opportunity that ensure the proper wiring of neural circuits, as well as windows of vulnerability when abnormal experience could cause lasting damage to the developing brain. In the visual system, critical period plasticity drives the establishment of binocularly matched orientation preferences in cortical neurons. Here, we show that binocular matching is completely blocked by monocular deprivation during the critical period. Moreover, environmental enrichment can fully rescue the disrupted matching, whereas conventional housing of twice the duration results in a partial rescue. We then use two-photon calcium imaging to track individual cells chronically during the EE-induced recovery, and reveal important insights into how appropriate function can be restored to the nervous system after the critical period.

\section{Introduction}

Neural circuits in the brain must integrate multiple channels of information to generate coherent perception of the outside world. In the visual system, for example, the central visual space is seen by both eyes in most mammals, and the two eyes' inputs are

\footnotetext{
Received Nov. 16, 2016; revised May 2, 2017; accepted May 5, 2017.

Author contributions: J.N.L. and J.C. designed research; J.N.L. and Y.G. performed research; J.N.L., H.C., and J.C. analyzed data; J.N.L. and J.C. wrote the paper.

This work was supported by NIH Grants EY020950 and EY026286 to J.C. We thank Jad Barchini and other members of the Cang laboratory for discussion; Dr. Na Ji and Dr. Wenzhi Sun from Janelia Farm Research Campus for the design of coverslips; and Vivek Jayaraman, Rex A. Kerr, Douglas S. Kim, Loren L. Looger, Karel Svoboda from the GENIE Project, Janelia Farm Research Campus, and Howard Hughes Medical Institute for the use of GCaMP6s.

The authors declare no competing financial interests.

Correspondence should be addressed to Dr. Jianhua Cang, Department of Neurobiology, Northwestern University, 2205 Tech Drive, Hogan 2-160, Evanston, IL 60208. E-mail: cang@northwestern.edu.

DOI:10.1523/JNEUROSCI.3534-16.2017

Copyright $\odot 2017$ the authors $\quad 0270-6474 / 17 / 375822-12 \$ 15.00 / 0$
}

relayed by the thalamus to converge onto the same neurons in the primary visual cortex (V1). These V1 neurons are selective for stimulus orientation and their orientation preferences are matched binocularly (Hubel and Wiesel, 1962; Nelson et al., 1977; Bridge and Cumming, 2001; Wang et al., 2010), a property presumably necessary for normal perception. Binocular integration is also a beneficial process because it helps to determine the relative distance of objects in the visual field (Cumming and DeAngelis, 2001). Similarly, inputs from the two ears are compared to determine the location of objects in auditory space (Knudsen et al., 1987). The auditory and visual maps are then aligned to facilitate multisensory integration (Cang and Feldheim, 2013). Importantly, these integrative circuits are often shaped by experience-dependent processes during so-called critical periods in development to ensure their proper wiring (Knudsen and Brainard, 1995; Espinosa and Stryker, 2012). 
The profound and enduring changes that take place during these critical periods also make them windows of vulnerability for developing neural circuits. A failure to receive appropriate sensory experience during the critical period would result in abnormal circuit formation and neural function that is difficult to repair later in life. For example, in the case of binocular matching, mouse V1 neurons are initially tuned to different orientations through the two eyes until approximately postnatal day (P)21, and the difference declines progressively to reach the adult level by P30 (Wang et al., 2013). This binocular matching process is prevented by visual deprivation during this period and the disrupted matching cannot spontaneously recover after the critical period (Wang et al., 2010).

Given its obvious clinical relevance, a number of studies have tried and succeeded in reactivating visual cortical plasticity in adult animals with the hope of reducing the deficits caused by early visual deprivation (Pizzorusso et al., 2002, 2006; He et al., 2006, 2007; Sale et al., 2007; Greifzu et al., 2014; Stodieck et al., 2014). However, these studies have almost exclusively focused on the restoration of ocular dominance plasticity or improvement of visual acuity, without examining binocular matching of orientation preference. In this study, therefore, we set out to determine whether binocular matching can be rescued by environmental enrichment (EE) following monocular visual deprivation spanning the entire critical period. The EE paradigm is noninvasive, as mice are free to engage an environment of greater complexity than conventional housing, with enhanced sensory, motor, and cognitive stimuli (Cancedda et al., 2004; Greifzu et al., 2014; Sale et al., 2007, 2014).

Using both single-unit electrophysiology and two-photon calcium imaging, we show that 3 weeks of EE can fully rescue the binocular matching deficit caused by visual deprivation during the critical period, whereas 6 weeks of conventional housing only results in a partial rescue. We then use chronic two-photon imaging to observe the matching process as it unfolds in individual cells during EE-induced rescue. Our results show that for cells that are clearly dominated by one of the two eyes, the input representing the weaker eye changes its orientation preference to align with that of the dominant eye, to achieve binocularly matched orientation preference. These studies thus reveal ocular dominance as a key driver of the binocular matching process, consistent with a Hebbian mechanism whereby the dominant input instructs the weaker input to adopt its tuning properties.

\section{Materials and Methods}

Mice. All animals were used in accordance with protocols approved by Northwestern University Institutional Animal Care and Use Committee. Wild-type C57BL/ 6 mice of both sexes were used in this study. They were housed on a $12 \mathrm{~h}$ light/dark cycle, with food and water available ad libitum either in conventional cages or under enriched conditions. The EE consisted of a larger cage $(18 \times 14 \times 8$ in $)$ that contained a number of toys, including crawl balls, pup tents, huts, tunnels, balls, and running wheels. The toys were repositioned once every week and replaced with new ones at least once during the 3 week enrichment period (Cancedda et al., 2004; Wang et al., 2013; Greifzu et al., 2014). Mice were housed with four to five other mice, matched in both age and sex. It is worth mentioning that a range of enrichment paradigms exists, with varying complexity of the toys and visual stimuli, the level of social interaction and the size of the cages (Cancedda et al., 2004; Greifzu et al., 2014). The paradigm in the current study was chosen to provide continuity with previous work from our laboratory on EE and binocular matching (Wang et al., 2013).

Monocular deprivation. We followed established protocols to perform monocular deprivation (MD; Gordon and Stryker, 1996; Cang et al.,
2005; Krishnan et al., 2015). In all cases, the right eye was sutured shut at $\mathrm{P} 19$ or P20, i.e., at the outset of the critical period. In this procedure, mice were anesthetized under $\sim 3 \%$ isoflurane in oxygen. After the hair was trimmed around the eyelids, the area was disinfected, and a small portion of the lids were removed, and the eye was flushed with saline. Two to three mattress sutures were placed using 7-0 silk (Ethicon), opposing the full extent of the trimmed lids. Animals recovered on a heating pad until they were alert and mobile. Animals were checked daily for the first week to ensure eyelid closure and proper healing. Following 3 weeks of deprivation, at $\sim \mathrm{P} 40$, the sutured eyelid was reopened. The mice were either used right away for recording/imaging, or left to recover in conventional housing or EE.

Extracellular recording. Mice were anesthetized with an intraperitoneal injection of urethane $(1.2 \mathrm{mg} / \mathrm{kg})$, and sedated with chlorprothixene (10 mg/kg, i.m.), following published procedures (Wang et al., 2010, 2013; Zhao et al., 2013, 2014). Atropine ( $0.3 \mathrm{mg} / \mathrm{kg}$ in $10 \%$ saline) and dexamethasone $(2.0 \mathrm{mg} / \mathrm{kg}$ in $10 \%$ saline) were also administered subcutaneously. The animals were then placed on a stereotaxic instrument. Their temperature was monitored with a rectal thermoprobe and maintained at $37^{\circ} \mathrm{C}$ through a feedback heater (Frederick Haer). A small craniotomy $\left(\sim 2 \mathrm{~mm}^{2}\right)$ was performed over the left hemisphere, at $2.8-3.3$ $\mathrm{mm}$ lateral from the midline and $0.5-0.8 \mathrm{~mm}$ anterior from the lambda suture to expose the binocular zone of V1. Tungsten microelectrodes (5-10 M $\Omega$, FHC) were positioned perpendicular to the pial surface, and lowered gradually until a unit was identified. In each animal, two to four penetrations were made with minimum spacing of $50 \mu \mathrm{m}$ and cells recorded across all layers were included in our analysis. Electrical signals, both spikes (filtered between 0.3 and $5 \mathrm{kHz}$ and sampled at $25 \mathrm{kHz}$ ) and field potentials (filtered between 10 and $300 \mathrm{~Hz}$ and sampled at $800 \mathrm{~Hz}$ ), were acquired using a System 3 workstation (Tucker Davis Technologies) and the spike waveforms were further sorted offline into single units using OpenSorter (Tucker Davis Technologies). The animals were overdosed with euthasol $(150 \mathrm{mg} / \mathrm{kg}$ pentobarbital; Virbac) at the end of recording.

Virus injection and cranial window implantation. For two-photon calcium imaging, GCaMP6s was expressed in binocular V1 using adenoassociated virus (AAV) purchased from the University of Pennsylvania Vector Core (AAV1.Syn.GCaMP6s.WPRE.SV40, titer of $2-3 \times 10^{13} \mathrm{GC} /$ $\mathrm{ml}$ ). For experiments with unmanipulated mice, the injection procedure was done at P40. For MD mice, this was performed at P27 (Fig. 1). During the procedure, mice were anesthetized under isoflurane $(\sim 3 \%$ for induction, $\sim 1 \%$ for maintenance). Dexamethasone was administered subcutaneously to reduce edema $(2.0 \mathrm{mg} / \mathrm{kg}$ in $10 \%$ saline). A circular craniotomy of $2.5 \mathrm{~mm}$ in diameter was centered over binocular V1. Subsequently, AAV-containing GCaMP6s (1:2 dilution in PBS) was injected, using a Nanoject II (Drummond) fitted with a glass pipette with a beveled tip at $45^{\circ}$ and with an inner diameter of $10-20 \mu \mathrm{m}$. Fifteen pulses of $2.3 \mathrm{nl}$ each ( $35 \mathrm{nl}$ total volume), at $20 \mathrm{~s}$ intervals, were delivered at $350 \mu \mathrm{m}$ below the surface.

Following injection, a cranial window consisting of two pieces of coverglass was implanted. The bottom coverglass (Zeiss, \#1.5), $2.5 \mathrm{~mm}$ in diameter, contacted the dura and filled the craniotomy. On top of this coverglass was a $4.0 \mathrm{~mm}$ coverslip, with a $2 \mathrm{~mm}$ diameter hole cut through the center (Potomac Photonics). The two cover glasses were bonded with ultraviolet cured optical adhesives (Norland Optical Adhesives 61) before the procedure, and cyanoacrylate glue was placed around the edge of the larger glass during the procedure to fix the window to the skull. This configuration allowed for imaging through one layer of glass and for no adhesive to contact the brain (Sun et al., 2016). A small metal bar was then mounted on the mouse's head with Metabond (Parkell), which would be clamped under the microscope to hold the mouse.

Two-photon imaging. Mice were sedated with chlorprothixene (10 mg/ $\mathrm{kg}$, i.m.). Anesthesia was then induced with $2 \%$ isoflurane in oxygen and maintained during imaging with $0.5-1 \%$ as needed. Imaging was performed with a two-photon microscope (2P-SGS, Bruker Nano Surface Division) and a Ti:sapphire laser (Coherent, Chameleon Ultra II) at an excitation wavelength of $920 \mathrm{~nm}$ and with a $40 \times / 0.8$ NA objective (Leica). A shield was placed around the craniotomy to block light from the visual stimulus during imaging. Data were acquired using Prai- 
rieView software with a spiral scan at $1.5 \times$ optical zoom, resulting in a circular field of view with a diameter of $180 \mu \mathrm{m}$. Image resolution was $256 \times 256$ pixels and the acquisition rate $6.061 \mathrm{~Hz}$. For chronic imaging, coordinates with a particular reference point within the window were established before the first imaging session following MD. The coordinates for each imaged field of view were stored and static high-resolution images were taken. Following EE, we used the coordinates to identify the areas imaged previously. The static images were used to ensure as close an alignment as possible to the original imaged areas.

Visual stimuli. Visual stimuli were generated with MATLAB programs developed originally by Dr. Cris Niell (Niell and Stryker, 2008) using the Psychophysics Toolbox extensions (Brainard, 1997; Pelli, 1997). For single-unit recording, a ViewSonic video monitor $(40 \times 30 \mathrm{~cm}$, $60 \mathrm{~Hz}$ refresh rate, $35 \mathrm{~cd} / \mathrm{m}^{2}$ mean luminance) was placed at $25 \mathrm{~cm}$ in front of the animal to display the stimuli, with its midline aligned with the animal. Sinusoidal gratings drifting perpendicular to their orientations were used to determine V1 neurons' orientation selectivity $(100 \%$ contrast and temporal frequency of 2 $\mathrm{Hz}$ ). Each trial lasted $1.5 \mathrm{~s}$, followed by an interstimulus period of $0.5 \mathrm{~s}$ when a gray screen of the mean luminance was shown. The drifting direction $(\theta)$ and spatial frequency of the gratings were varied between $0-330^{\circ}$ (12 steps at $30^{\circ}$ spacing) and $0.01-0.08$ cycle/degree (cpd; in 4 logarithmic steps) in a pseudorandom order, for a total of five trials for each direction.

For two-photon imaging of calcium signals, the stimulus was presented on a LCD monitor $\left(37.5 \times 30 \mathrm{~cm}, 60 \mathrm{~Hz}\right.$ refresh rate, $\sim 50 \mathrm{~cd} / \mathrm{m}^{2}$ mean luminance). Drifting sinusoidal gratings of 12 directions $\left(0-330^{\circ}, 30^{\circ}\right.$ steps $)$ were presented for $2 \mathrm{~s}$, at a temporal frequency of $2 \mathrm{~Hz}$ and a spatial frequency of $0.04 \mathrm{cpd}$. The interstimulus interval was $5 \mathrm{~s}$, to accommodate the slow decay kinetics of GCaMP6s (Chen et al., 2013). The gratings were presented in a pseudorandom order, for a total of five trials for each direction.

Data analysis. For extracellular recording data, we calculated the response magnitude $(R)$ as the average spike rate during the $1.5 \mathrm{~s}$ presentation of each direction and spatial frequency combination, subtracted with the spontaneous rate determined by blank condition presentation. We determined for each cell the preferred direction as the one that gave the largest response when averaged across all spatial frequencies. The cell's orientation tuning was then analyzed at the spatial frequency that gave maximum response at this direction. Specifically, the responses across all directions at this spatial frequency, $R(\theta)$, were used to calculate $\frac{\sum \mathrm{R}(\theta) \mathrm{e}^{2^{*} \mathrm{i}^{*} \theta}}{\sum \mathrm{R}(\theta)}$ which is the normalized vector sum of the responses in the $180^{\circ}$ orientation space. Its amplitude was used as a global orientation selective index (gOSI), which is the same as 1-circular variance (Ringach et al., 2002; Mazurek et al., 2014). Half of its complex phase was calculated and then converted to the preferred orientation (pref_O) by subtracting $90^{\circ}$, to confine pref_O between $-90^{\circ}$ to $90^{\circ}$ (Wang et al., 2010; Sarnaik et al., 2014). The difference in the preferred orientation between the two eyes was calculated by subtracting ipsilateral pref_O from contralateral pref_O along the $180^{\circ}$ cycle, and differences $>90^{\circ}$ would be subtracted from $180^{\circ}$ to convert them to values between
0 and $90^{\circ}$. The absolute value of this interocular difference in preferred orientation, which we refer to as $\Delta \mathrm{O}$, was used in all quantifications.

The two-photon imaging data were analyzed using a custom MATLAB program which was originally written by a former laboratory member Dr. Samsoon Inayat (Inayat et al., 2015). First, all collected frames of individual time-series were averaged, and regions-of-interest (ROIs) were selected on the average images, where cell bodies were clearly identifiable. The ROIs were polygons drawn manually on the edge of the cell bodies to measure the intracellular calcium signal with minimal contamination by neuropil activity. The intensity values for all pixels in each ROI were averaged for each frame to obtain the raw temporal calcium signal of the respective cell. From the raw signal, for each stimulus presentation, the relative change in the fluorescence signal from the baseline, i.e., $\Delta F / F_{0}=\left(F-F_{0}\right) / F_{0}$, was calculated as follows. $F_{0}$ was the mean of the baseline signal over a fixed interval before stimulus onset. The fixed interval was the last $25 \%$ of the duration between stimulus offset and next onset, which was chosen as $5 \mathrm{~s}$, to allow the fluorescence signal from the previous stimulus presentation to decay sufficiently to baseline. $F$ was the mean fluorescence signal from $250 \mathrm{~ms}$ after stimulus onset to $500 \mathrm{~ms}$ 
after stimulus offset. A cell was considered responsive to drifting gratings if it met the following criterion: its mean fluorescence during the visual stimulus period (as defined by $F$ above) was more than 2 SDs above the mean baseline fluorescence $\left(F_{0}\right)$, for at least one of the stimulus conditions (of the 12 directions). The mean value of $\Delta F / F_{0}$ for each direction was then used to determine the preferred orientation, gOSI, and $\Delta \mathrm{O}$ for every responsive cell, following the same equations as described above for single-unit data.

To confirm that the above procedure was a reliable approach to identify truly responsive cells, we also devised a bootstrapping-based test for responsiveness. The null hypothesis underlying the test was that there was no difference between the prestimulus baseline fluorescence signals and the signals during stimulus presentation. Accordingly, for each trial of each stimulus direction, the $\Delta F / F$ values of the eight frames which comprised the prestimulus windows $(\sim 1.33 \mathrm{~s})$ were averaged (all resulting values were very close to 0 ). The same calculation was performed for the 13 frames comprising the stimulus window for each trial. The resulting 10 values for the five trials were combined. To test our hypothesis, we randomly sampled 10 numbers with replacement from these 10 values. These values were in turn split into two groups of five, the mean of each group was calculated, and the difference of the two means taken. This procedure was repeated for a total of 10,000 rounds, resulting in a distribution of difference of the mean values. We then determined whether the experimentally observed difference between the prestimulus and stimulus groups fell within the $95 \%$ confidence interval of the bootstrapped distribution. If that was the case, the cell would be deemed nonresponsive to that particular direction; otherwise, the null hypothesis would be rejected and the cell deemed responsive to that direction. We performed this bootstrapping method in all cells and found that $98 \%$ of the cells from the unmanipulated mice deemed responsive by the original method were deemed responsive by bootstrapping ( $n=169 / 172$ cells), $96 \%$ for the EE group ( $n=106 / 110$ cells), and $96 \%$ for the MD group $(n=$ $542 / 562$ cells). This close agreement between the two methods gives us confidence that the cells we included in our analysis were truly responsive. All values reported in Results were from the first method of testing responsiveness.

To determine how much neuropil contamination could affect our results, we performed the following analysis in a subset of cells. For each ROI, we subtracted from its $F$ the mean intensity of pixels in a $20 \mu \mathrm{m}$ shell surrounding it (Kerlin et al., 2010; Chen et al., 2013): $F_{\text {Cell }}=F_{\mathrm{ROI}}-r \times$ $F_{\text {Neuropil }}$, where $r$, the neuropil contamination factor, is an estimate of the ratio of mean fluorescence present in small diameter blood vessels compared with the surrounding neuropil. We calculated $r$ to be $\sim 0.3$ in our study ( $40 \times, 0.8$ NA objective), compared with $r=0.3-0.4$ for $25 \times, 1.05$ NA objective by Kerlin et al. (2010) and $r=0.7$ for $16 \times, 0.8$ NA by Chen et al. (2013). Any cell whose neuropil shell encompassed a second cell, even partially, was excluded from this analysis. We compared the calculated gOSI and preferred orientation with and without neuropil subtraction and reported the analysis in Results.

For analysis of $\Delta \mathrm{O}$ as a function of orientation selectivity, the two respective gOSI values through contralateral and ipsilateral eyes were averaged for each cell to indicate their degree of selectivity. The ocular dominance index (ODI) for each cell was calculated as $(C-I) /(C+I)$, where $C$ and $I$ represent the maximum response magnitude, averaged across all trials, to 1 of the 12 directions of drifting gratings for the contralateral and ipsilateral eyes, respectively (Cang et al., 2005). The ODI ranges from -1 to 1 , where positive values indicate contralateral bias and negative values indicate ipsilateral bias.

For analysis of the chronic imaging data, the average images of the entire T-series for a given field-of-view were compared between the two time points. Only cells which could be clearly identified as the same were included in the analysis. Furthermore, only cells responsive to both monocular stimulations at both imaging time points, as per the criteria described above, were included.

Statistics. All pooled data were presented as mean \pm SEM. Statistical significance was calculated using nonparametric, two-sided, Wilcoxon signed rank test or Kolmogorov-Smirnov (K-S) test. All analyses and graph plotting were performed in MATLAB (MathWorks).

\section{Results}

\section{EE rescues binocular matching of orientation preference}

Previously, our laboratory showed that binocular neurons in V1 are tuned to similar orientations through the two eyes in adult mice, and that this binocular matching of orientation preference is largely blocked by visual deprivation during the critical period (Wang et al., 2010). In the previous study, MD was initiated at P24, when the binocular matching process had already started (Wang et al., 2013). In the current study, we determined the effect of MD that spanned the entire critical period, and more importantly, tested whether EE can rescue binocular matching in postcritical period mice following this long-term visual deprivation.

First, we monocularly deprived mice from P19/20, the outset of the critical period, until $\mathrm{P} 40, \sim 10 \mathrm{~d}$ after binocular matching typically reaches the adult level. Upon reopening the deprived eye at P40, we performed single-unit recording across all cortical layers in the binocular zone of V1 contralateral to the deprived eye (Fig. $1 B$ ), and assessed the monocular orientation tuning of each unit using drifting sinusoidal gratings. As expected, binocular matching was completely disrupted by MD. The interocular difference of the preferred orientation, which we refer to as " $\Delta \mathrm{O}$ ", was almost evenly distributed between $0^{\circ}$ and $90^{\circ}$ (Fig. $2 B$ ), with a mean of $47.3^{\circ} \pm 5.0^{\circ}(n=30$, from 5 mice $)$. Indeed, the distribution of $\Delta \mathrm{O}$ was not statistically different from a random matching between the two eyes, which would result in a uniform distribution between 0 and $90^{\circ}$ with a mean of $45^{\circ}(p=0.64$, one-sample $\mathrm{K}-\mathrm{S}$ test). In contrast, in normal, unmanipulated adult mice (Fig. $1 A$ ), most cells had $\Delta \mathrm{O}$ smaller than $20^{\circ}$ (Fig. $2 A)$, with a mean of $22.0 \pm 3.4^{\circ}(n=39$, from 6 mice, $p=8.6 \times$ $10^{-5}$, two-sample $\mathrm{K}-\mathrm{S}$ test compared with MD group; Fig. $3 A$ ), nearly identical to what was previously shown (Wang et al., 2013).

We next determined whether binocular matching could be rescued merely by the restoration of normal vision following MD. We returned a group of mice to conventional housing for 3 weeks after reopening the deprived eye at P40 (Fig. 1C). A slight trend of improvement was seen in these mice after this substantial period of restored binocular visual experience, but their binocular matching (mean $\Delta \mathrm{O}=36.5 \pm 3.3^{\circ}, n=54$ cells from 7 mice) was not statistically better than in mice immediately following $\mathrm{MD}$ ( $p=0.136$, two-sample K-S test) and was significantly worse than the unmanipulated controls $(p=0.001$; Figs. $2 C, 3 A)$. The trend of improvement in matching became statistically significant with 6 weeks in conventional housing $\left(\Delta \mathrm{O}=32.5 \pm 3.3^{\circ}\right.$, $n=46$ cells from 6 mice, $p=0.04$ compared with post-MD; Figs. $2 D, 3 A)$, but the degree of matching was still significantly worse than the unmanipulated controls $(p=0.003$, two-sample K-S test). In other words, MD spanning the entirety of the critical period resulted in a mismatch of orientation preferences that cannot spontaneously recover with subsequent binocular visual experience.

Next, to determine whether EE could rescue the disrupted matching following MD, we placed another group of mice in cages that were larger than the standard ones and included toys and running wheels (Fig. 1D). After just 3 weeks of EE, $>60 \%$ of cells from these mice had closely aligned orientation preferences $\left(\leq 20^{\circ}\right)$ through the two eyes. The overall $\Delta \mathrm{O}$ (mean $=24.6^{\circ} \pm$ $3.2^{\circ}, n=59$ cells from 8 mice) was significantly better than that of conventional housing controls that had identical or even longer recovery time ( $p=0.001$ two-sample $\mathrm{K}-\mathrm{S}$ test compared with 3 weeks in convention housing; and $p=3.56 \times 10^{-4}$ compared with 6 weeks), and in fact reached the level of normal unmanipulated adults $(p=0.37$; Figs. $2 E, 3 A)$. For comparison, we also 
housed mice in $\mathrm{EE}$ at the same age, for 3 weeks following normal binocular visual experience (Fig. 1E). No significant difference in the distribution of $\Delta \mathrm{O}$ values was observed in these mice $\left(\Delta \mathrm{O}=22.9 \pm 2.7^{\circ}\right.$, $n=47$ cells from 7 mice; Fig. $2 F$ ) compared with mice kept in conventional housing $(p=0.89$; Fig. $3 A)$. In other words, 3 weeks of EE did not further improve the degree of binocular matching in unmanipulated mice, but was enough for a robust rescue of binocular matching following MD during the critical period.

Finally, the binocular mismatch of orientation preference seen in the MD group could potentially be due to the reduced response magnitude in these mice, which in the most extreme case, would lead to inaccurate determination of preferred orientation. To address this possibility, we examined the relationship between $\Delta \mathrm{O}$ and response magnitude. Specifically, we chose for individual neurons the peak response through the weaker of the two eyes and grouped them according to this response magnitude. As shown in Figure 3B, $\Delta \mathrm{O}$ was always larger in the MD group than the EE group, even when cells with similar response magnitude were compared (first bin: $\mathrm{EE} \Delta \mathrm{O}=28.2^{\circ} \pm 6.6^{\circ}$, $n=13$ cells; $\mathrm{MD} \Delta \mathrm{O}=43.2^{\circ} \pm 6.7^{\circ}, n=$ 16 cells; second bin: $\mathrm{EE} \Delta \mathrm{O}=31.8^{\circ} \pm$ $8.7^{\circ}, n=11$ cells; $\mathrm{MD} \Delta \mathrm{O}=60.8^{\circ} \pm 8.3^{\circ}$, $n=5$ cells; and third bin: $\Delta \mathrm{OEE}=21.0^{\circ} \pm$ $4.0^{\circ}, n=35$ cells, $\mathrm{MD} \Delta \mathrm{O}=46.7^{\circ} \pm 10.9^{\circ}$, $n=9$ cells). Note that the response magnitude was calculated after subtracting the spontaneous rate following previous studies (Niell and Stryker, 2008; Liu et al., 2009; Wang et al., 2010). The spontaneous rate was low and similar in these two groups of mice (MD: $0.41 \pm 0.10$ and EE: $0.60 \pm 0.15$ spikes/s). Together, these results thus indicate that the mismatch of preferred orientation in the deprived mice held true across different response magnitudes.

\section{Two-photon imaging of binocular matching and its rescue by $\mathrm{EE}$}

Previous findings about binocular matching relied solely on single-unit recording. In the current study, we used two-photon calcium imaging, which afforded us the opportunity to not only record from a larger number of cells in a given animal, but also track the same cells over time, in a chronic fashion, as the process of matching unfolded during EE-induced rescue.

We first demonstrated the practicality of using two-photon imaging to study binocular matching by verifying the high degree of matching in unmanipulated adult mice. We imaged the activity of layer $2 / 3$ cells in response to drifting sinusoidal gratings presented separately to each eye (Fig. 4). Gratings elicited robust responses in the imaged cells through the two eyes (Fig. 4B). Many cells had
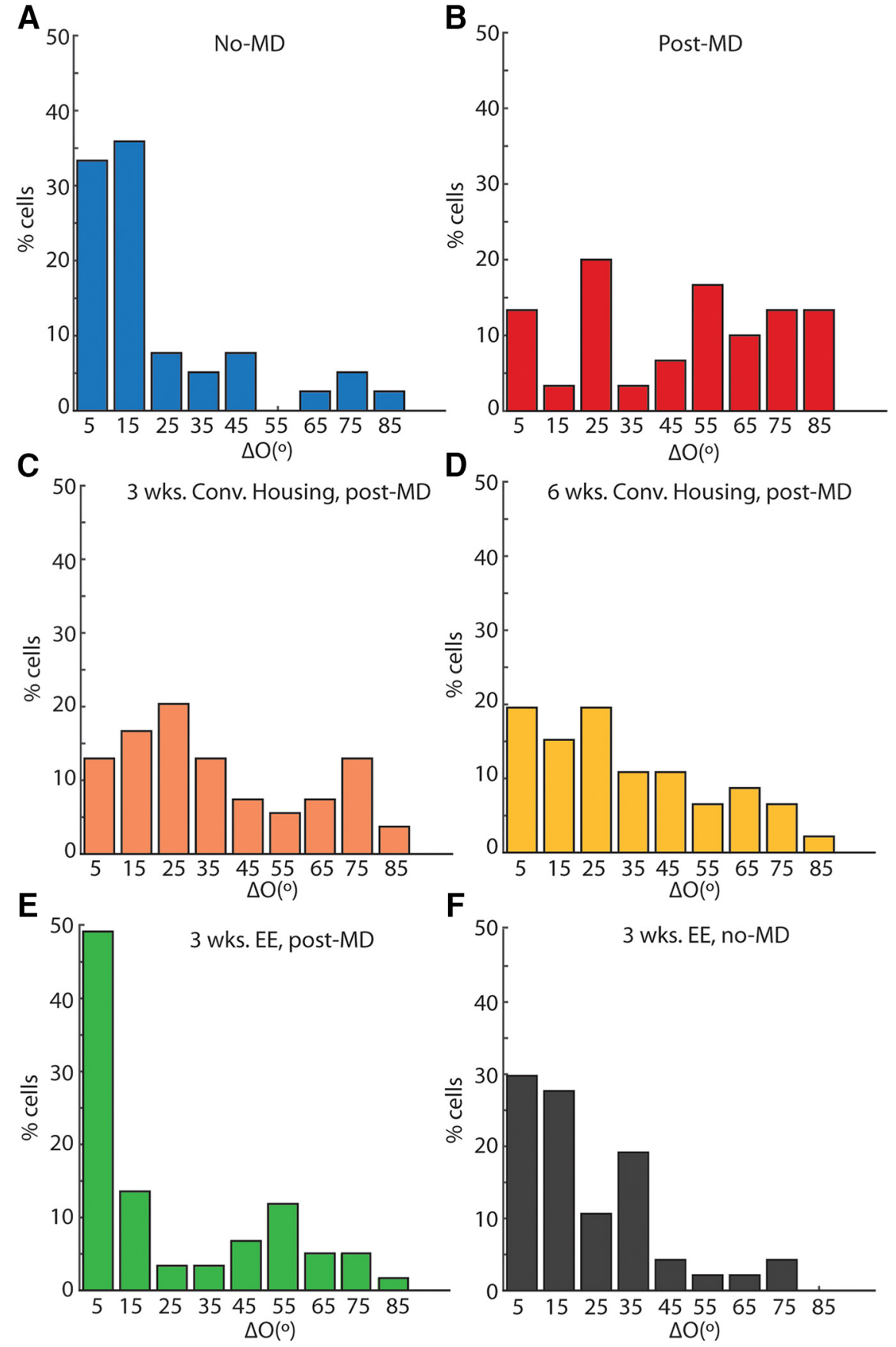

Figure 2. EE is required for the rescue of binocular matching. $A-F$, Distribution of interocular difference of preferred orientation $\left({ }^{\prime \prime} \Delta 0^{\prime \prime}\right)$ in six experimental groups: $(\boldsymbol{A})$ unmanipulated adult controls (no-MD; $\Delta 0=22.0^{\circ} \pm 3.4^{\circ}, n=39$ cells; 5 mice); (B) immediately after monocular deprivation (mean $\Delta 0=47.3^{\circ} \pm 5.0^{\circ} ; n=30$ cells; 6 mice); (C) 3 weeks of conventional cage recovery $\left(\Delta 0=36.5^{\circ} \pm 3.3^{\circ} ; n=54\right.$ cells; 7 mice $) ;(D) 6$ weeks of conventional cage recovery $\left(\Delta 0=32.6^{\circ} \pm 3.4^{\circ} ; n=46\right.$ cells; 6 mice); (E) recovery in EE (EE post-MD; $\Delta 0=24.6^{\circ} \pm 3.2^{\circ}, n=59$ cells; 8 mice); and $(\boldsymbol{F}) 3$ weeks of EE in unmanipulated mice (EE no-MD; $\Delta 0=22.9^{\circ} \pm 2.7^{\circ}, n=47$ cells; 7 mice). The six groups correspond to the schematics in Figure $1 A-E$.

monocular orientation preferences that were closely aligned binocularly (Fig. $4 B, D$ ). At the population level, close to $50 \%$ of the responsive cells had a $\Delta \mathrm{O}$ of $20^{\circ}$ or less (mean $26.4^{\circ} \pm 4.7^{\circ}, n=176$ cells from 5 mice; Fig. $5 A$ ). In contrast, in animals imaged immediately after $\mathrm{MD}$ (Fig. $4 C, E$ ), the preferred orientations were completely unmatched (Fig. $5 B$; mean $=44.2 \pm 1.1^{\circ}, n=562$ from 16 mice; $p=0.30$, one-sample $\mathrm{K}-\mathrm{S}$ test compared with random matching and $p=1.7 \times 10^{-8}$, two-sample $\mathrm{K}-\mathrm{S}$ test with unmanipulated controls), confirming the results obtained by single-unit recording. 
A

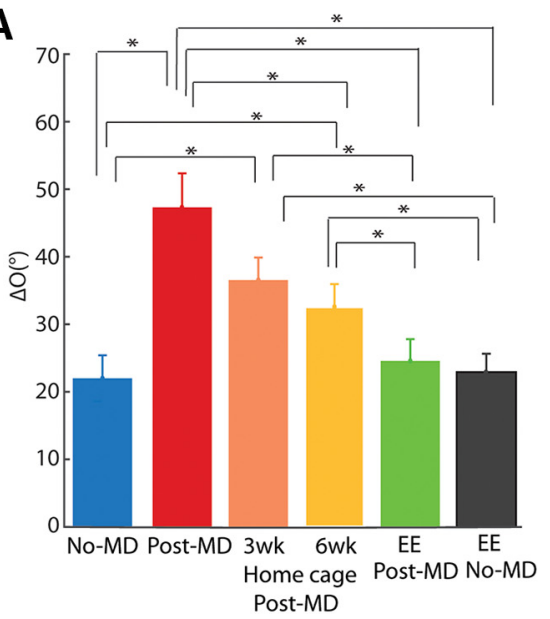

B

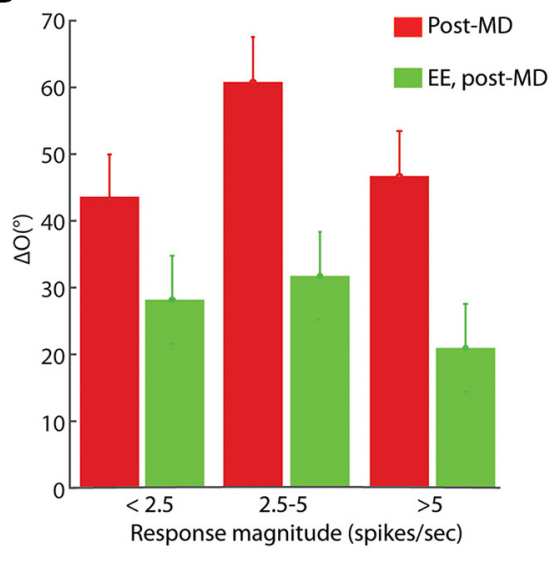

Figure 3. Quantification of EE-induced recovery of binocular matching. $\boldsymbol{A}$, Mean $\Delta 0$ for the six groups shown in Figure 2 ( ${ }^{*}$ statistically significant difference; those not noted were not statistically different. See main text for $p$ values). $\boldsymbol{B}, \Delta 0$ as a function of response magnitude for cells from the MD and EE-recovery groups. Cells were binned by their peak response magnitude through whichever eye was weakest (first bin: $\mathrm{EE} \Delta 0=28.2^{\circ} \pm 6.6^{\circ}, n=13$ cells; MD $\Delta 0=43.2^{\circ} \pm 6.7^{\circ}, n=16$ cells; second bin: EE $\Delta 0=31.8^{\circ} \pm 8.7^{\circ}, n=11$ cells; $\mathrm{MD} \Delta 0=60.8^{\circ} \pm 8.3^{\circ}, n=5$ cells; and third bin: $\Delta 0 \mathrm{EE}=21.0^{\circ} \pm 4.0^{\circ}, n=35$ cells; MD $\Delta 0=46.7^{\circ} \pm 10.9^{\circ}, n=9$ cells).

To better understand the range of the observed $\Delta \mathrm{O}$ values, we compared the level of matching in individual cells with the orientation selectivity of each cell (as quantified by its gOSI; see Materials and Methods for details of calculation). In the unmanipulated control mice, cells with low gOSI showed $\Delta \mathrm{O}$ values that spanned the entire $0-90^{\circ}$ range (Fig. $4 D$ ), likely reflecting the fact the preferred orientation was less precisely defined in these cells. On the other hand, the stronger orientation preferences of cells that had high gOSIs were less likely subject to fluctuation, and were able to precisely align themselves to each other through the two eyes. In contrast, this inverse relationship between $\Delta \mathrm{O}$ and gOSI was absent in the MD mice (Fig. $5 E$ ), where the $\Delta O$ values of the highly selective cells were distributed within the entire range between 0 and $90^{\circ}$. This finding indicates that the increased $\Delta \mathrm{O}$ following MD is not due to an absence of orientation selective cells, but is instead to the lack of a binocular matching process in these animals.

We then studied the effect of EE on binocular matching following long-term MD spanning the entire critical period using two-photon imaging. Three weeks of EE was able to improve binocular matching in these mice and reduce $\Delta \mathrm{O}$ to the level seen in unmanipulated adults (Fig. $5 C$; mean $=27.4 \pm 1.2^{\circ}, n=110$ cells from 4 animals, $p=0.14$ compared with controls, $\mathrm{K}-\mathrm{S}$ test). The normal inverse relationship between $\Delta \mathrm{O}$ and gOSI seen in unmanipulated mice was also seen in these mice (Fig. $5 F$ ), confirming the rescue of binocular matching by EE.

An important technical concern with two-photon calcium imaging is the possible contamination of cell bodies' calcium signals by the surrounding neuropil (Kerlin et al., 2010; Chen et al., 2013). We performed neuropil subtraction on a subset of movies and compared parameters of the responses to those determined without subtraction (see Materials and Methods). As expected, the gOSI (Fig. $4 F$ ) was consistently greater with neuropil subtraction than without $(0.36 \pm 0.01$, compared with $0.30 \pm$ 0.01 without subtraction; $p=6.85 \times 10^{-19}$, Wilcoxon signed rank test), because a largely nonselective component was subtracted over all directions. But importantly, there was a strong correlation between the values with or without neuropil subtraction $(r=0.95)$. Furthermore, the preferred orientation (Fig. 4G)

was nearly identical for most cells regardless of whether neuropil subtraction was done or not $(r=0.85)$. Because the preferred orientation was a parameter of central importance to our study of binocular matching, this result gave us confidence in the values we obtained without performing neuropil subtraction. Furthermore, the neuropil contamination factor, which we calculated to be 0.3 (see Materials and Methods), is only an estimation and may not be the same for every cell. For these reasons, we reported values in the following analysis without performing neuropil subtraction.

\section{Chronic imaging of EE-induced recovery of binocular matching}

We next sought to understand the process underlying EE's rescue of binocular matching. A limitation of all previous studies was that matching was assessed acutely, without observing how the process played out in individual cells. Now, with two-photon calcium imaging, we were able to follow the matching process chronically, observing the same cells over time as it unfolded. Specifically, we performed the first imaging session immediately after the 3 weeks of MD. The mice were allowed to wake up from light anesthesia (see Materials and Methods) and were subsequently placed in EE for 3 weeks. Following EE, we imaged the same locations in these mice and determined the binocular matching of re-identified cortical cells (Fig. $1 F)$.

Overall, we obtained 45 cells which we were able to identify confidently at both time points (from 4 mice; Fig. 6A-E). These 45 cells represented a substantial proportion of the total number of cells imaged following $\mathrm{EE}$ ( $n=110$, as presented in the previous section). Just like the whole population, these cells were highly mismatched immediately after MD (Fig. $6 B$; mean $\Delta \mathrm{O}=$ $52.7^{\circ} \pm 3.5^{\circ}, n=45$, Fig. $\left.6 E, F\right)$ and then experienced a substantial improvement in matching as the result of EE (Fig. $6 D$; mean $\Delta \mathrm{O}=21.0^{\circ} \pm 2.3$, Fig. $\left.6 E, F\right)$. Significantly, the vast majority of these cells ( $n=38 / 45,84 \%)$ showed an improvement in matching during $\mathrm{EE}$ (i.e., a decrease in their $\Delta \mathrm{O}$; Fig. $6 E$ ). We thus focused our subsequent analysis on these cells to further understand the binocular matching process.

An important feature of binocular neurons is ocular dominance; that is, their inputs from the two eyes are of different relative strength. We therefore examined whether the initial ocular dominance at the onset of the matching process could predict the matching outcome. To do this, we calculated an ODI (see Materials and Methods for details) for each cell after MD, before EE-induced matching. The ODI ranges between -1 and 1 , with positive values indicating contralateral bias and negative values ipsilateral bias. We then calculated how much these cells changed their monocular orientation preferences during EE, separately for contralateral and ipsilateral tuning. This analysis revealed an interesting pattern where the dominant eye's input was less likely to change its orientation preference than was the weaker one's. For example, when looking at the cells' orientation preferences through the ipsilateral eye (Fig. $7 A$ ), a clustering of points with small changes was seen at the more negative values of the ODI range (i.e., ipsilateral dominance). In fact, for cells that had an ODI $\leq-0.33$ (i.e., ipsilateral input was more than twice as strong 
A

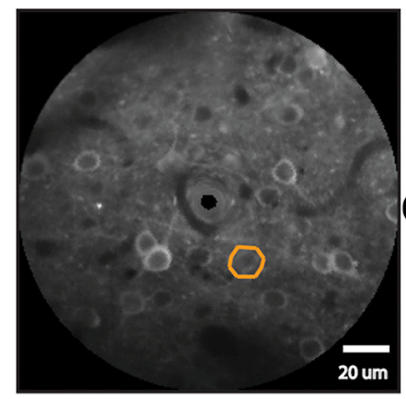

D No-MD

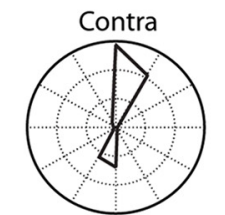

E

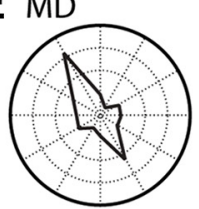

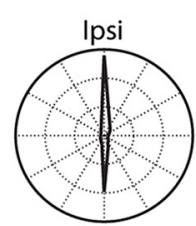

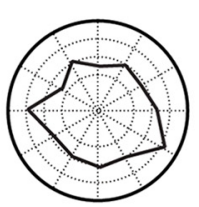

B No-MD

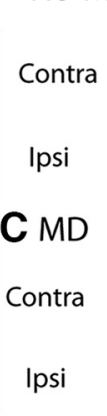

$\mathbf{F}$

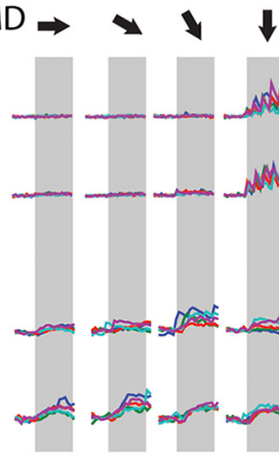

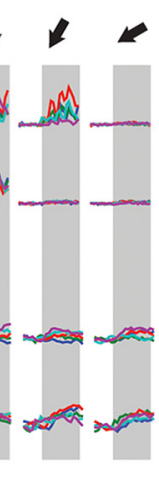

G
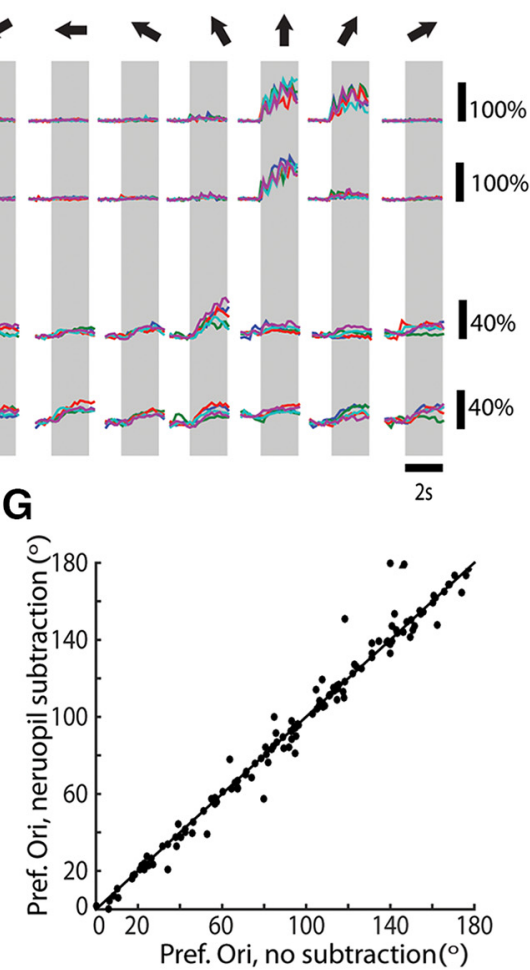

Figure 4. Two-photon calcium imaging of binocular matching. $A$, An example field-of-view from an unmanipulated P60 mouse expressing the calcium indicator GCaMP6s. $B$, Calcium traces from the ROI marked in $A$. Top row of traces are from contralateral stimulation; bottom row from ipsilateral stimulation. The gray boxes mark the duration of stimulation and arrows on top indicate the directions of the drifting gratings for each set of trials. Each colored trace was from one individual trial. Black scale bars indicate change in fluorescence, $\Delta F / F$. $C$, Same as in $B$, but from a mouse immediately following MD. $\boldsymbol{D}, \boldsymbol{E}$, Polar plots based on responses in $\boldsymbol{B}$ and $\boldsymbol{C}$, respectively. Scale bars: $\boldsymbol{D}$, both outermost circles $=150 \% \Delta F / F_{0} ; \boldsymbol{E}$, left, $40 \% \Delta F / F_{0}$ right, $25 \%$. $\boldsymbol{F}, S$ catter plot of g0SI of a population of cells analyzed with and without neuropil subtraction. Note that gOSI is highly correlated in individual cells between the two methods ( $r=0.95, n=135$ cells; 9 mice), and that neuropil subtraction tended to increase the gOSI (gOSI with subtraction $=0.36 \pm 0.01$; without subtraction $=0.30 \pm 0.01, p=6.85 \times 10^{-19}$, Wilcoxon signed rank test). $\boldsymbol{G}$, Same as in $\boldsymbol{F}$, but comparing preferred orientation ( $r=0.85, n=135$ cells).

as the contralateral input), their orientation preference through the ipsilateral eye changed very little (mean $\Delta \mathrm{ipsi}=11.1^{\circ} \pm$ $3.2^{\circ}, n=11$ cells). In comparison, for cells that were dominated by the contralateral eye (ODI $\geq 0.33$ ), their changes in ipsilateral orientation preference were much greater $\left(\right.$ mean $\Delta$ ipsi tuning $=57.6^{\circ} \pm$ $6.7^{\circ}, n=15$ cells; Fig. 7A). On the other hand, these contralaterally dominated cells (ODI $\geq 0.33$ ) did not change their contralateral tuning as much (mean $\Delta$ contra tuning $=16.8^{\circ} \pm 3.9^{\circ}, n=15$ cells; Fig. $7 D$ ), consistent with the notion that the orientation preference through the dominant eye is more stable during EE-induced matching.

The contralaterally dominated cells also displayed a wide range in the change of ipsilateral preference (Fig. $7 A$ ). We reasoned that this wide range could reflect how much these cells "needed" to change their orientation preference through the ipsilateral eye to match binocularly. To test this idea, we compared for these cells $(\mathrm{ODI} \geq 0.33)$ the amount of ipsilateral preference change (Fig. $7 B ; y$-axis) and the amount of binocular mismatch at the onset of $\mathrm{EE}(B ; x$-axis). A significant correlation was indeed seen between the two (Fig. $7 B ; r=0.63, p=0.01$ ). A similar correlation was (F) $\mathrm{EE}(r=-0.19, p=0.04)$.
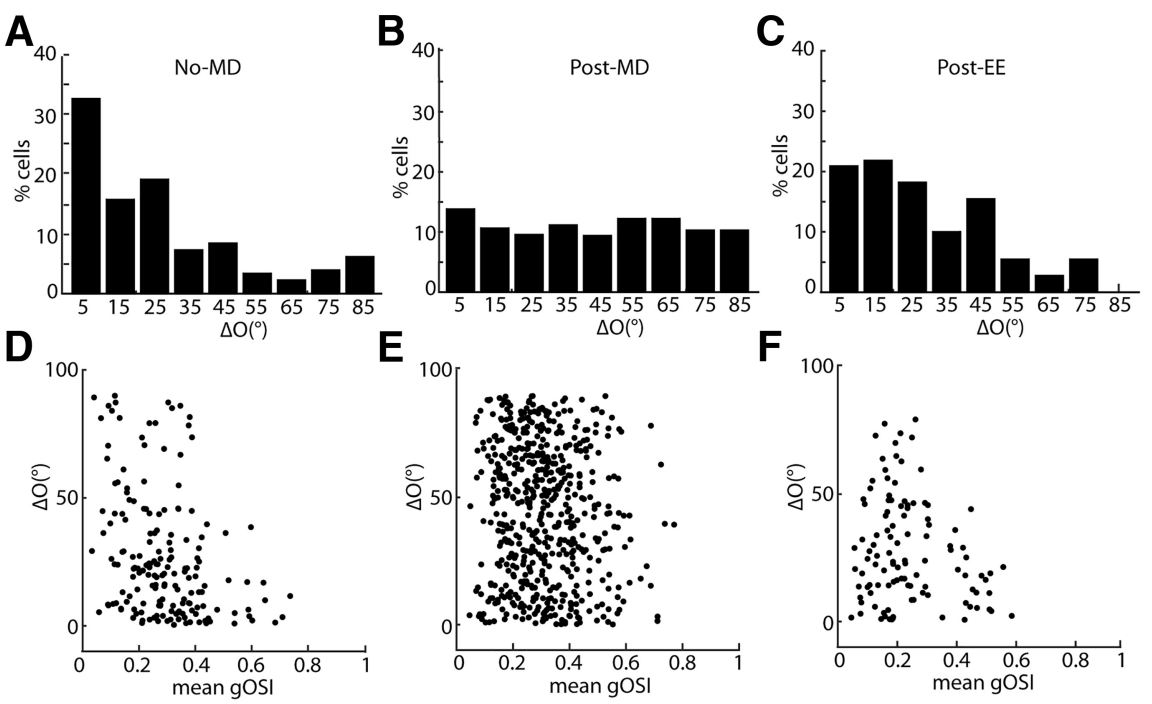

$\mathbf{F}$

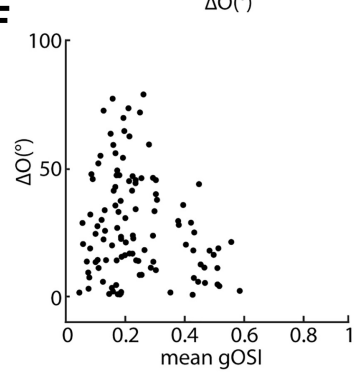

Figure 5. Two-photon imaging of EE-induced rescue of binocular matching. $\boldsymbol{A}-\boldsymbol{C}$, Histogram of $\Delta 0$ for $(\boldsymbol{A})$ non-MD control (mean $\Delta 0=26.4^{\circ} \pm 4.7^{\circ}, n=176,4$ mice); $(B)$ post-MD $\left(\Delta 0=44.1^{\circ} \pm 1.2^{\circ}, n=562\right.$ cells, 16 mice $) ;$ and $(C)$ post-EE $(\Delta 0=$ $27.4^{\circ} \pm 1.2^{\circ}, n=110$ cells, 4 mice). $\boldsymbol{D}-\boldsymbol{F}$, Scatter plots of $\Delta 0$ as a function of orientation selectivity for individual cells (mean gOSI of the 2 monocular tuning curves) for (D) non-MD control $\left(r=-0.34, p=3 \times 10^{-6}\right) ;(\boldsymbol{E})$ post-MD $(r=-0.02, p=0.09)$; and

obtained when considering the change in contralateral preference in cells dominated by the ipsilateral eye (ODI $\leq-0.33$; Fig. $7 F ; r=0.64, p=0.03)$. In other words, the variance in the change of preferred orientation through the weaker eye can largely be 
A

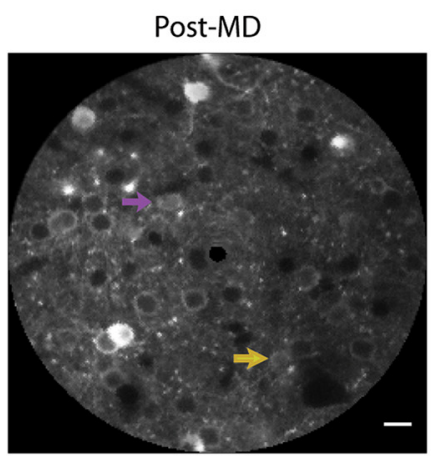

C

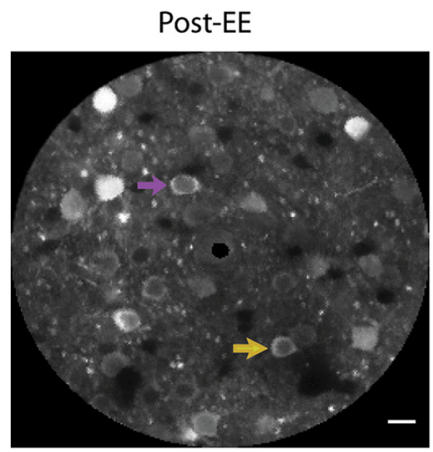

E

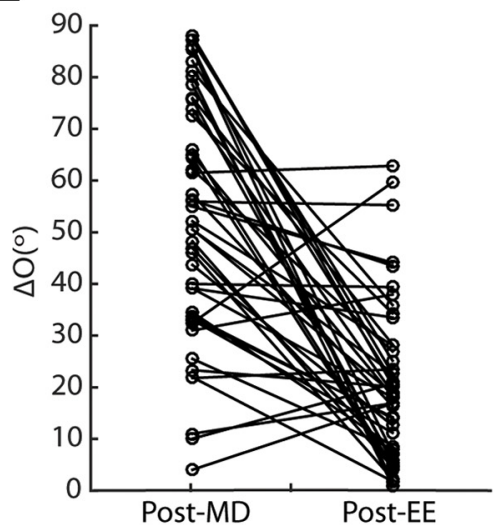

B
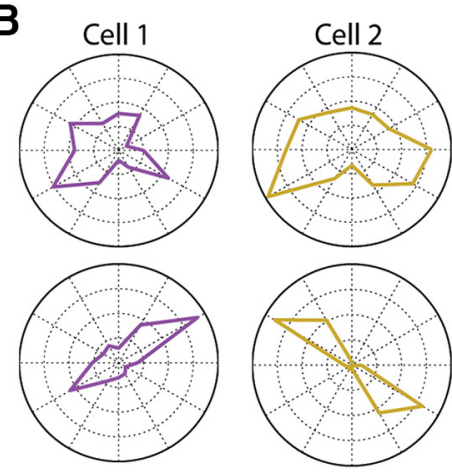

Contra

D
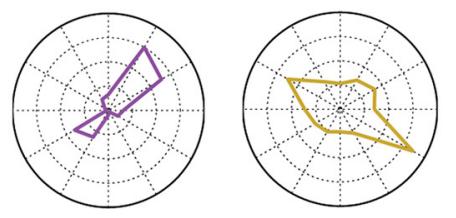

Contra
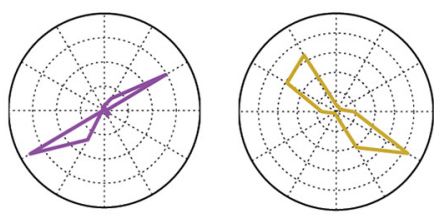

F

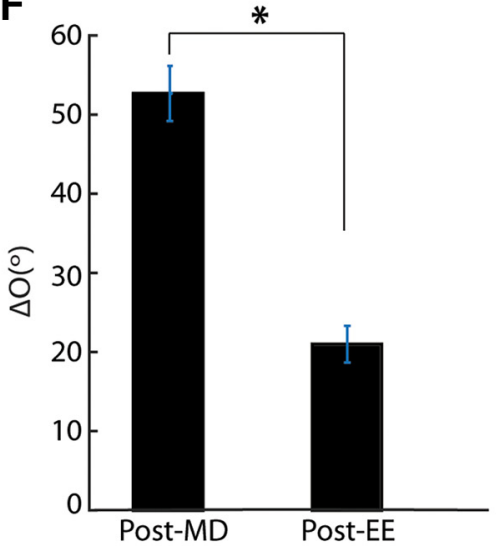

Figure 6. Tracking EE-induced binocular matching by chronic two-photon calcium imaging. $A$, Averaged image of field-of-view from a mouse immediately following MD. Scale bars, $20 \mu \mathrm{m}$. $\boldsymbol{B}$, Polar plots of responses from the two cells highlighted in $\boldsymbol{A}$ to drifting gratings presented separately to contralateral eye (top; outermost circle $=40 \% \Delta F / F_{0}$ for cell $1,40 \% \Delta F / F_{0}$ for cell 2 ) and ipsilateral eye (bottom; outermost circle $=80 \% \Delta F / F_{0}$ for cell 1, 200\% $\Delta F / F_{0}$ for cell 2). C, Same field-of-view as in $\boldsymbol{A}$, imaged again following 3 weeks of environmental enrichment. $\boldsymbol{D}$, Polar plots of the same two example cells from $\boldsymbol{A}$ following EE $(200 \%$ $\Delta F / F_{0}$ for cell $1,80 \% \Delta F / F_{0}$ for cell $2 ; 200 \% \Delta F / F_{0}$, cell $1150 \% \Delta F / F_{0}$ for cell 2$) . E, \Delta 0$ values for all cells imaged chronically, following MD and again EE ( $n=45$ cells; 4 mice). Note that the vast majority ( $n=38 / 45,84 \%$ ) showed a decrease in their $\Delta 0$. $\boldsymbol{F}$, Mean $\Delta 0$ for the cells shown in scatter plot after MD (mean $\left.\Delta 0=52.7^{\circ} \pm 3.5\right)$ and then again following $\mathrm{EE}\left(\Delta 0=21.0^{\circ} \pm\right.$ $\left.2.3^{\circ},{ }^{*} p<0.05\right)$.

explained by how mismatched these cells were immediately following MD. On the other hand, these cells' orientation preferences through the dominant eye remained relatively stable regardless of their initial mismatch (Figs. $7 C ; r=0.36, p=0.27 ; 7 E ; r=0.32, p=$ $0.24)$. Together, these results indicate that during the EE-induced rescue, for cells that are clearly dominated by one of the two eyes, the input representing the weaker eye changes its orientation preference to align with that of the dominant eye, to achieve binocularly matched orientation preferences.

Finally, we examined potential changes in the degree of orientation selectivity during the matching process. Immediately following $\mathrm{MD}$, the dominant responses started off much more orientation selective (Fig. $7 G$; gOSI $=0.41 \pm 0.02$ ) than the weak responses $(\mathrm{gOSI}=0.19 \pm 0.02$, $p=2 \times 10^{-5}$, Wilcoxon signed rank test). After 3 weeks of EE, the selectivity of the dominant responses remained virtually unchanged (Fig. $7 G$; gOSI $=0.40 \pm 0.03$, $p=0.89$, Wilcoxon signed rank test). In contrast, the weak orientation selectivity through the nondominant eye significantly improved following $\mathrm{EE}$ (gOSI = $0.29 \pm 0.02, p=0.035$, Wilcoxon signed rank test). These results thus suggest that the initial binocular mismatch in these cells was partially due to the fact that orientation preference is poorly defined for the weakly tuned responses through the nondominant eye. The responses through the nondominant eye became more selective during EE while also becoming aligned with the orientation preferences through the dominant eye.

However, it is important to note that the above scenario is not the only case in EE-induced matching. A substantial population of cells was robustly tuned through both eyes before $\mathrm{EE}$ ( $\mathrm{gOSI} \geq 0.20$ through both eyes, $n=12 / 38$ cells; Fig. 6 , cell 2 ). These cells were also completely mismatched after $\mathrm{MD}\left(\Delta \mathrm{O}=47.1^{\circ} \pm 5.2^{\circ}\right)$ and became much better matched after $\mathrm{EE}(\Delta \mathrm{O}=$ $22.5^{\circ} \pm 3.9^{\circ}$; Fig. $7 H ; p=4.9 \times 10^{-4}$, Wilcoxon signed rank test). In other words, the well defined orientation tuning in these cells, especially the ones through the nondominant eye, shifted during EE to achieve binocular matching. The other cells $(n=26)$, which had gOSI $<0.2$ through at least one eye, also matched significantly during $\mathrm{EE}$ (from $\Delta \mathrm{O}=62.8 \pm$ $3.8^{\circ}$ to $16.8^{\circ} \pm 2.7^{\circ}$; Fig. $7 H ; p=8.3 \times$ $10^{-6}$, Wilcoxon signed rank test). In fact, when the final $\Delta \mathrm{O}$ (i.e., after $\mathrm{EE}$ ) was plotted against the initial gOSI (i.e., before EE) of the nondominant responses for all cells, no significant correlation was seen (Fig. $7 I ; r=0.17, p=0.31$ ). This result thus indicates that, regardless of how selective these cells were at the beginning of the matching process, their orientation preferences through the nondominant eye were able to align with that through the dominant eye during EE, either by acquiring higher orientation selectivity and/or by shifting their preferred orientation, thereby reaching a similar degree of binocular matching.

\section{Discussion}

In the present study, we have demonstrated that EE can rescue binocular matching following monocular deprivation spanning the entire critical period. Indeed, this EE-induced process was able to lower the interocular difference of V1 neurons' orientation preferences to the level seen in unmanipulated mice. Fur- 
A

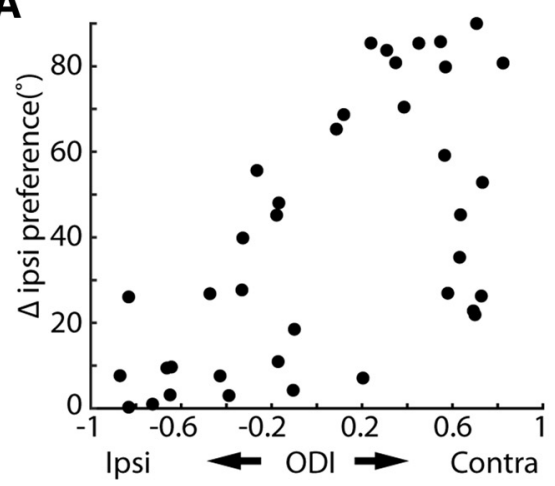

D
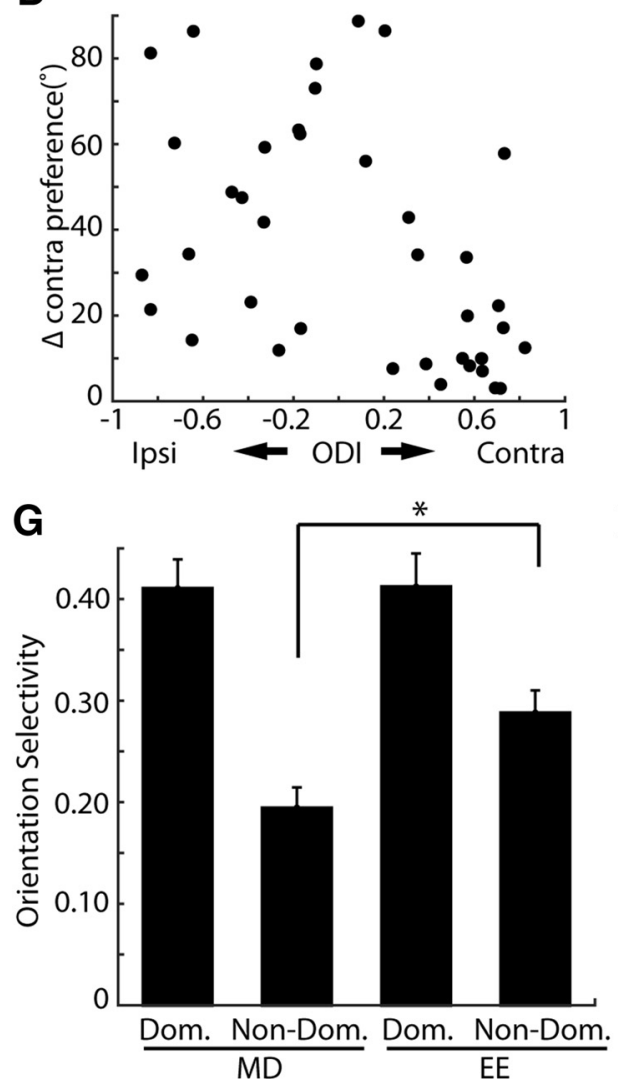

B

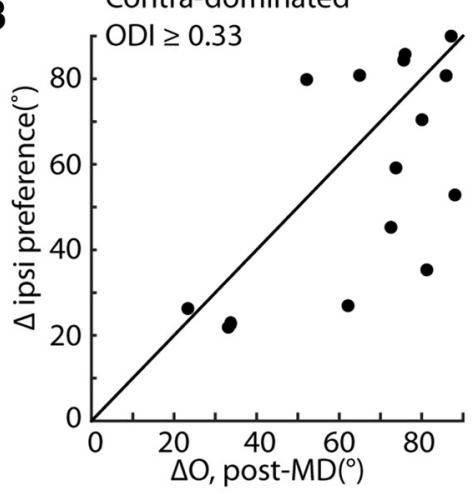

E

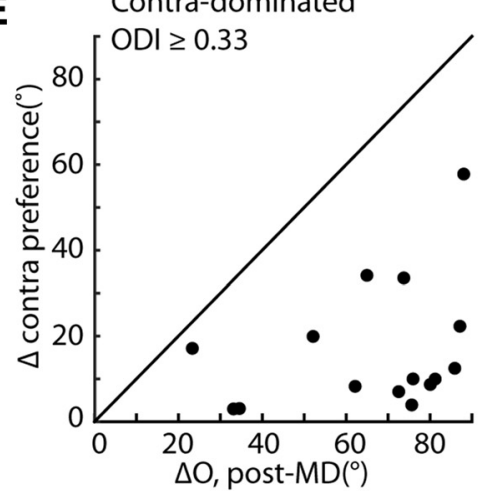

C

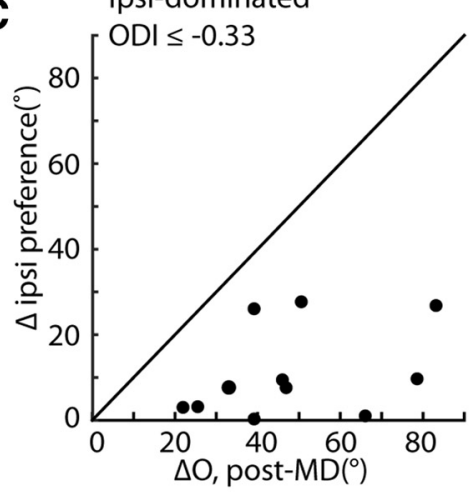

F

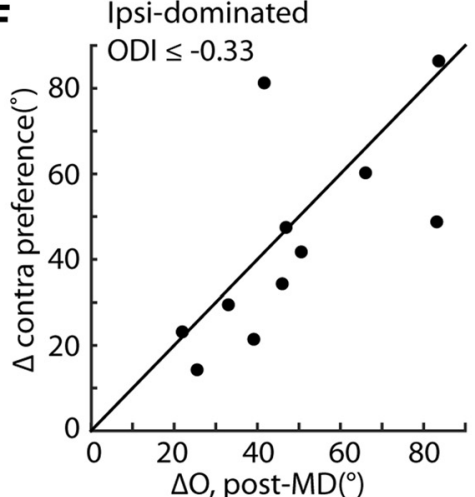

H

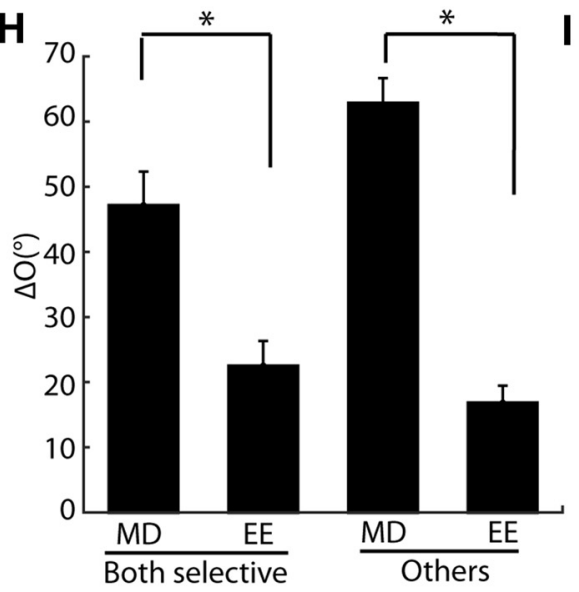

I

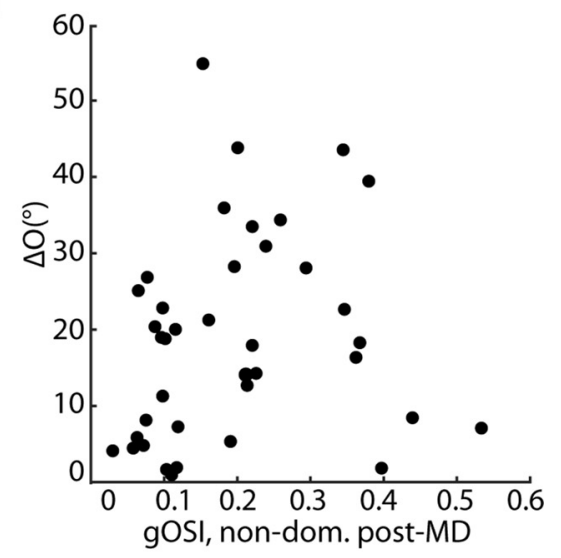

Figure 7. EE-induced binocular matching depends on ocular dominance, as revealed by chronic imaging. $\boldsymbol{A}$, Scatter plot of the change in the ipsilateral eye's orientation preference during EE (" $\Delta$ ipsi preference") versus the initial ODI immediately following MD. B, Scatter plot of " $\Delta$ ipsi preference" versus the amount of binocular mismatch (" $\Delta 0$ ") immediately following MD, in cells dominated by the contralateral eye (ODI $\geq 0.33$ ). $\boldsymbol{C}$, Scatter plot of $\Delta$ ipsi preference versus $\Delta 0$ following MD in cells dominated by the ipsilateral eye (0DI $\leq-0.33$ ). $\boldsymbol{D}-\boldsymbol{F}$, Same plots as in $\boldsymbol{A}-\boldsymbol{C}$, except for the change in the contralateral eye's orientation preference (" $\Delta$ contra preference"). G, Mean gOSI values through the dominant (Dom) and nondominant (Non-Dom) eye after MD and EE. The mean gOSI values of the four bars are as follows: $0.41 \pm 0.02 ; 0.19 \pm 0.02 ; 0.40 \pm 0.03 ;$ and $0.29 \pm 0.02$ ( $n=38$ cells). The weak orientation selectivity through the nondominant eye improved significantly during $\mathrm{EE}$ ( $p=0.035$, Wilcoxon signed rank test). $\boldsymbol{H}$, Mean $\Delta 0$ values for cells that were highly selective through both eyes ( $\mathrm{g} 0 \mathrm{SI} \geq 0.2,2$ leftmost bars) and others ( $\mathrm{g} 0 \mathrm{SI}<$ 0.2 through at least one eye) following MD and EE. The $\Delta 0$ values of the four bars are as follows: $47.1^{\circ} \pm 5.2^{\circ}, 22.5^{\circ} \pm 3.9^{\circ}\left(n=12\right.$ cells); and $62.8^{\circ} \pm 3.8^{\circ}, 16.8^{\circ} \pm 2.7^{\circ}(n=26$ cells). Both groups showed significant matching during $\mathrm{EE}\left(p=4.88 \times 10^{-4}\right.$ and $8.29 \times 10^{-6}$, respectively; Wilcoxon signed rank test). $I$, Scatter plot of the final $\Delta 0$ as a function of the initial gOSI through the nondominant response following $\mathrm{MD}(r=0.17, p=0.31)$.

thermore, we have used chronic two-photon calcium imaging to track the matching process, and identified a key role for ocular dominance in determining the matching outcome.

EE and adult plasticity

Whether neural circuit function can be restored following sensory deprivation is an important question in neuroscience research. Since Hubel and Wiesel's (1970) pioneering studies on the effects of monocular deprivation in developing cats, numer- ous studies and model systems have been used to explore the possibility of reopening critical period plasticity in adulthood (Levine et al., 2015). Most of these studies have focused on ocular dominance plasticity, either by studying whether it can be induced in adult animals after certain manipulations (Pizzorusso et al., 2002; McGee et al., 2005; He et al., 2006; Morishita et al., 2010; Kuhlman et al., 2013; Davis et al., 2015), or by examining whether normal ocular dominance can be restored in animals that had 
been deprived in early life (He et al., 2007; Sale et al., 2007; Maya Vetencourt et al., 2008; Kaneko and Stryker, 2014). Many studies have also examined whether the reduced visual acuity in the deprived animals could be improved by newly induced adult plasticity (He et al., 2007; Sale et al., 2007; Maya Vetencourt et al., 2008; Morishita et al., 2010; Stephany et al., 2014; Davis et al., 2015). In contrast, whether binocular matching of orientation preference, a key outcome of critical period plasticity during normal development, can be rescued following long-term visual deprivation had only been examined in one study (Kaneko and Stryker, 2014).

In the current study, we build on previous work from our laboratory by showing that monocular deprivation spanning the entire critical period completely prevents binocular matching from taking place. This deficit is long lasting, as even 6 weeks of binocular visual experience in conventional housing is unable to induce a full rescue. In contrast, we show that the disrupted matching can be rescued by 3 weeks of EE. This rescue broadly recapitulates the outcome of the matching process observed during the critical period. Compared with conventional housing, EE provides animals with opportunities for enhanced sensory, motor, and cognitive stimulation (Diamond et al., 1964). It is a naturalistic manipulation because mice are left to interact with the environment as they choose. Our studies thus indicate that EE can potentially be used as a noninvasive paradigm to recover normal binocularity following early visual deficits.

How does EE promote adult plasticity to rescue binocular matching? In the only other study that examined recovery of binocular matching (Kaneko and Stryker, 2014), forced visual stimulation was paired with running on a treadmill in head-fixed mice and the recovery of visual functions was stimulus-specific. Such a combination of locomotion and visual stimulation is no doubt present in EE, as running wheels and larger space promote physical exercise. It is also likely that mice encounter a greater range of visual stimuli in EE and the recovery of visual functions is broader. As for the locus of its effect on binocular matching, EE was shown to reduce intracortical inhibition and perineuronal net density in adulthood following MD (Sale et al., 2007; Greifzu et al., 2014), two key factors in developmental critical period plasticity (Hensch, 2005; Espinosa and Stryker, 2012; Levelt and Hübener, 2012). In addition, EE may induce epigenetic modulations in the visual system to promote cortical plasticity (Wang et al., 2013; Baroncelli et al., 2016). When considering these mechanisms, it would be important to determine whether extending the recovery time in conventional housing beyond 6 weeks could lead to a full rescue of binocular matching. In one scenario for how binocular matching is rescued, EE may merely accelerate the process which occurs at a slow rate in conventional housing, due to age-dependent decline of cortical plasticity (Lehmann and Löwel, 2008). In the second scenario, EE may be in fact needed to fully rescue binocular matching, which it does by engaging additional mechanisms of cortical plasticity. Future studies will be needed to reveal the exact circuit and molecular mechanisms underlying EE's effect on binocular matching.

\section{Ocular dominance and binocular matching}

By using chronic two-photon calcium imaging, we have shown that for cells that are clearly dominated by one of the two eyes, the input representing the weaker eye changes its orientation preference to align with that of the dominant eye, which itself remains relatively constant during the matching process. This finding provides an important clue to a complete understanding of binocular matching in the visual cortex.

V1 layer 2/3 neurons are preferentially connected with other excitatory neurons that are tuned to similar orientations (Ko et al., 2011; Lee et al., 2016). At the same time, they still receive inputs that are individually tuned to a wide range of orientations (Jia et al., 2010). The binocular matching process likely involves the changes of these individual synapses. Given that V1 neurons are more often activated by the dominant eye, it is conceivable that the dominant eye's inputs instruct the change of the weak eye's tuning through Hebbian plasticity. In such a scenario, synapses activated through the weak eye that are tuned to the same orientation as the dominant eye's input would take part in the firing of the postsynaptic neuron as the animal is exposed to that orientation in the visual scene. As a result, these synapses would be strengthened. Conversely, the weak eye's synapses that are tuned to orientations different from the dominant eye's preferred orientations are less likely to take part in the firing of the cortical neuron, and are consequently weakened. In this way, the tuning through the weak eye comes to match with the dominant eye's orientation preference. Furthermore, it has been shown that EE promotes dendritic branching and synaptogenesis in adult visual cortex (Volkmar and Greenough, 1972; Bhide and Bedi, 1984; Briones et al., 2004). It is thus possible that new synapses may be formed on to layer $2 / 3$ cells during EE-induced rescue, in addition to the strengthening and weakening of existing synapses, which are then subsequently modified via Hebbian mechanisms.

It is important to note that the above matching scenario applies to the cells that exhibit clear ocular dominance (a ratio of 2:1 or greater in peak response magnitude), which account for twothirds of cells in our dataset. We did not reveal a clear pattern of binocular matching for the other third of cells, which fell in the middle of the OD range. It is possible that some of these cells adopt certain level of ocular dominance first during the EEinduced recue, as a precursor to matching. A dominant eye would then be able to instruct the nondominant eye to match its orientation preference. In addition, even cells with strong eye preference post-MD would change their OD level during the recovery. How changing OD might influence matching of orientation preference, and whether such OD changes take place normally during critical period in the absence of deprivation, are important questions in understanding binocular matching. Further chronic studies with intermediate imaging time points will be needed to address these questions.

Finally, a few cells in our experiments did not show any improved matching during $\mathrm{EE}(n=7 / 45)$. It is possible that additional time was needed for these cells to match. It is also possible that at least some of these cells would not match under normal circumstances anyway. We note that even in unmanipulated animals, there is a population of cells with large differences in preferred orientation through the two eyes. Whether or not it is advantageous for the visual system to have a range of orientation mismatch is an interesting possibility. Further work elucidating the mechanisms of binocular matching will hopefully yield insight into this question.

In conclusion, we have demonstrated that $\mathrm{EE}$ is an effective way to rescue disrupted binocular matching caused by visual deprivation during the critical period. By chronically following the matching process, our experiments provide important information for understanding the mechanisms underlying binocular development. The revealed mechanisms may be generalizable to the development of other systems that need to integrate multiple sources of inputs to subserve normal neural functions. 


\section{References}

Baroncelli L, Scali M, Sansevero G, Olimpico F, Manno I, Costa M, Sale A (2016) Experience affects critical period plasticity in the visual cortex through an epigenetic regulation of histone post-translational modifications. J Neurosci 36:3430-3440. CrossRef Medline

Bhide PG, Bedi KS (1984) The effects of a lengthy period of environmental diversity on well-fed and previously undernourished rats: II. Synapse-toneuron ratios. J Comp Neurol 227:305-310. CrossRef Medline

Brainard DH (1997) The psychophysics toolbox. Spat Vis 10:433-436. CrossRef Medline

Bridge H, Cumming BG (2001) Responses of macaque V1 neurons to binocular orientation differences. J Neurosci 21:7293-7302. Medline

Briones TL, Klintsova AY, Greenough WT (2004) Stability of synaptic plasticity in the adult rat visual cortex induced by complex environment exposure. Brain Res 1018:130-135. CrossRef Medline

Cancedda L, Putignano E, Sale A, Viegi A, Berardi N, Maffei L (2004) Acceleration of visual system development by environmental enrichment. J Neurosci 24:4840-4848. CrossRef Medline

Cang J, Feldheim DA (2013) Developmental mechanisms of topographic map formation and alignment. Annu Rev Neurosci 36:51-77. CrossRef Medline

Cang J, Kalatsky VA, Löwel S, Stryker MP (2005) Optical imaging of the intrinsic signal as a measure of cortical plasticity in the mouse. Vis Neurosci 22:685-691. CrossRef Medline

Chen TW, Wardill TJ, Sun Y, Pulver SR, Renninger SL, Baohan A, Schreiter ER, Kerr RA, Orger MB, Jayaraman V, Looger LL, Svoboda K, Kim DS (2013) Ultrasensitive fluorescent proteins for imaging neuronal activity. Nature 499:295-300. CrossRef Medline

Cumming BG, DeAngelis GC (2001) The physiology of stereopsis. Annu Rev Neurosci 24:203-238. CrossRef Medline

Davis MF, Figueroa Velez DX, Guevarra RP, Yang MC, Habeeb M, Carathedathu MC, Gandhi SP (2015) Inhibitory neuron transplantation into adult visual cortex creates a new critical period that rescues impaired vision. Neuron 86:1055-1066. CrossRef Medline

Diamond MC, Krech D, Rosenzweig MR (1964) The effects of an enriched environment on the histology of the rat cerebral cortex. J Comp Neurol 123:111-120. CrossRef Medline

Espinosa JS, Stryker MP (2012) Development and plasticity of the primary visual cortex. Neuron 75:230-249. CrossRef Medline

Gordon JA, Stryker MP (1996) Experience-dependent plasticity of binocular responses in the primary visual cortex of the mouse. J Neurosci 16: 3274-3286. Medline

Greifzu F, Pielecka-Fortuna J, Kalogeraki E, Krempler K, Favaro PD, Schlüter OM, Löwel S (2014) Environmental enrichment extends ocular dominance plasticity into adulthood and protects from stroke-induced impairments of plasticity. Proc Natl Acad Sci U S A 111:1150-1155. CrossRef Medline

He HY, Hodos W, Quinlan EM (2006) Visual deprivation reactivates rapid ocular dominance plasticity in adult visual cortex. J Neurosci 26:29512955. CrossRef Medline

He HY, Ray B, Dennis K, Quinlan EM (2007) Experience-dependent recovery of vision following chronic deprivation amblyopia. Nat Neurosci 10: 1134-1136. CrossRef Medline

Hensch TK (2005) Critical period plasticity in local cortical circuits. Nat Rev Neurosci 6:877-888. CrossRef Medline

Hubel DH, Wiesel TN (1962) Receptive fields, binocular interaction and functional architecture in the cat's visual cortex. J Physiol 160:106-154. CrossRef Medline

Hubel DH, Wiesel TN (1970) The period of susceptibility to the physiological effects of unilateral eye closure in kittens. J Physiol 206:419-436. CrossRef Medline

Inayat S, Barchini J, Chen H, Feng L, Liu X, Cang J (2015) Neurons in the most superficial lamina of the mouse superior colliculus are highly selective for stimulus direction. J Neurosci 35:7992-8003. CrossRef Medline

Jia H, Rochefort NL, Chen X, Konnerth A (2010) Dendritic organization of sensory input to cortical neurons in vivo. Nature 464:1307-1312. CrossRef Medline

Kaneko M, Stryker MP (2014) Sensory experience during locomotion promotes recovery of function in adult visual cortex. eLife 3:e02798. CrossRef Medline

Kerlin AM, Andermann ML, Berezovskii VK, Reid RC (2010) Broadly tuned response properties of diverse inhibitory neuron subtypes in mouse visual cortex. Neuron 67:858-871. CrossRef Medline

Knudsen EI, Brainard MS (1995) Creating a unified representation of visual and auditory space in the brain. Annu Rev Neurosci 18:19-43. CrossRef Medline

Knudsen EI, du Lac S, Esterly SD (1987) Computational maps in the brain. Annu Rev Neurosci 10:41-65. CrossRef Medline

Ko H, Hofer SB, Pichler B, Buchanan KA, Sjöström PJ, Mrsic-Flogel TD (2011) Functional specificity of local synaptic connections in neocortical networks. Nature 473:87-91. CrossRef Medline

Krishnan K, Wang BS, Lu J, Wang L, Maffei A, Cang J, Huang ZJ (2015) $\mathrm{MeCP} 2$ regulates the timing of critical period plasticity that shapes functional connectivity in primary visual cortex. Proc Natl Acad Sci U S A 112:E4782-4791. CrossRef Medline

Kuhlman SJ, Olivas ND, Tring E, Ikrar T, Xu X, Trachtenberg JT (2013) A disinhibitory microcircuit initiates critical-period plasticity in the visual cortex. Nature 501:543-546. CrossRef Medline

Lee WC, Bonin V, Reed M, Graham BJ, Hood G, Glattfelder K, Reid RC (2016) Anatomy and function of an excitatory network in the visual cortex. Nature 532:370-374. CrossRef Medline

Lehmann K, Löwel S (2008) Age-dependent ocular dominance plasticity in adult mice. PLoS One 3:e3120. CrossRef Medline

Levelt CN, Hübener M (2012) Critical-period plasticity in the visual cortex. Annu Rev Neurosci 35:309-330. CrossRef Medline

Levine JN, Gu Y, Cang J (2015) Seeing anew through interneuron transplantation. Neuron 86:858-860. CrossRef Medline

Liu BH, Li P, Li YT, Sun YJ, Yanagawa Y, Obata K, Zhang LI, Tao HW (2009) Visual receptive field structure of cortical inhibitory neurons revealed by two-photon imaging guided recording. J Neurosci 29:10520-10532. CrossRef Medline

Maya Vetencourt JF, Sale A, Viegi A, Baroncelli L, De Pasquale R, O’Leary OF, Castrén E, Maffei L (2008) The antidepressant fluoxetine restores plasticity in the adult visual cortex. Science 320:385-388. CrossRef Medline

Mazurek M, Kager M, Van Hooser SD (2014) Robust quantification of orientation selectivity and direction selectivity. Front Neural Circuits 8:92. CrossRef Medline

McGee AW, Yang Y, Fischer QS, Daw NW, Strittmatter SM (2005) Experience-driven plasticity of visual cortex limited by myelin and Nogo receptor. Science 309:2222-2226. CrossRef Medline

Morishita H, Miwa JM, Heintz N, Hensch TK (2010) Lynx1, a cholinergic brake, limits plasticity in adult visual cortex. Science 330:1238-1240. CrossRef Medline

Nelson JI, Kato H, Bishop PO (1977) Discrimination of orientation and position disparities by binocularly activated neurons in cat straite cortex. J Neurophysiol 40:260-283. Medline

Niell CM, Stryker MP (2008) Highly selective receptive fields in mouse visual cortex. J Neurosci 28:7520-7536. CrossRef Medline

Pelli DG (1997) The VideoToolbox software for visual psychophysics: transforming numbers into movies. Spat Vis 10:437-442. CrossRef Medline

Pizzorusso T, Medini P, Berardi N, Chierzi S, Fawcett JW, Maffei L (2002) Reactivation of ocular dominance plasticity in the adult visual cortex. Science 298:1248-1251. CrossRef Medline

Pizzorusso T, Medini P, Landi S, Baldini S, Berardi N, Maffei L (2006) Structural and functional recovery from early monocular deprivation in adult rats. Proc Natl Acad Sci U S A 103:8517-8522. CrossRef Medline

Ringach DL, Shapley RM, Hawken MJ (2002) Orientation selectivity in macaque V1: diversity and laminar dependence. J Neurosci 22:5639-5651. Medline

Sale A, Maya Vetencourt JF, Medini P, Cenni MC, Baroncelli L, De Pasquale R, Maffei L (2007) Environmental enrichment in adulthood promotes amblyopia recovery through a reduction of intracortical inhibition. Nat Neurosci 10:679-681. CrossRef Medline

Sale A, Berardi N, Maffei L (2014) Environment and brain plasticity: towards an endogenous pharmacotherapy. Physiol Rev 94:189-234. CrossRef Medline

Sarnaik R, Wang BS, Cang J (2014) Experience-dependent and independent binocular correspondence of receptive field subregions in mouse visual cortex. Cereb Cortex 24:1658-1670. CrossRef Medline

Stephany CÉ, Chan LL, Parivash SN, Dorton HM, Piechowicz M, Qiu S, McGee AW (2014) Plasticity of binocularity and visual acuity are differ- 
entially limited by nogo receptor. J Neurosci 34:11631-11640. CrossRef Medline

Stodieck SK, Greifzu F, Goetze B, Schmidt KF, Löwel S (2014) Brief dark exposure restored ocular dominance plasticity in aging mice and after a cortical stroke. Exp Gerontol 60:1-11. CrossRef Medline

Sun W, Tan Z, Mensh BD, Ji N (2016) Thalamus provides layer 4 of primary visual cortex with orientation- and direction-tuned inputs. Nat Neurosci 19:308-315. CrossRef Medline

Volkmar FR, Greenough WT (1972) Rearing complexity affects branching of dendrites in the visual cortex of the rat. Science 176:1445-1447. CrossRef Medline

Wang BS, Sarnaik R, Cang J (2010) Critical period plasticity matches binoc- ular orientation preference in the visual cortex. Neuron 65:246-256. CrossRef Medline

Wang BS, Feng L, Liu M, Liu X, Cang J (2013) Environmental enrichment rescues binocular matching of orientation preference in mice that have a precocious critical period. Neuron 80:198-209. CrossRef Medline

Zhao X, Chen H, Liu X, Cang J (2013) Orientation-selective responses in the mouse lateral geniculate nucleus. J Neurosci 33:12751-12763. CrossRef Medline

Zhao X, Liu M, Cang J (2014) Visual cortex modulates the magnitude but not the selectivity of looming-evoked responses in the superior colliculus of awake mice. Neuron 84:202-213. CrossRef Medline 